\title{
Use of Carbon-11 Acetate and Dynamic Positron Emission Tomography to Assess Regional Myocardial Oxygen Consumption in Patients with Acute Myocardial Infarction Receiving Thrombolysis or Coronary Angioplasty
}

\author{
Victor Kalff, MB, BS, Rodney J. Hicks, MB, BS, Gary Hutchins, PhD, \\ Eric Topol, MD, and Markus Schwaiger, MD
}

\begin{abstract}
Carbon-11 (C-11) acetate has been introduced for the noninvasive measurements of myocardial oxygen consumption. This study was designed to assess regional C-11 acetate clearance in patients with acute myocardial infarction. Thirty-one patients were studied within 8 days of acute myocardial infarction. C-11 acetate washout-rate constants were significantly lower in the infarct territory than in the remote myocardium (p $<0.008$ ). The scintigraphic measurements correlated with heart rate-blood pressure product in the remote as well as infarct areas (0.52 and 0.48 , respectively). There was no significant correlation to left ventricular ejection fraction. C-11 washout rates were significantly affected by $\beta$ receptor therapy as assessed by multiple regression analysis. Thus, C-11 acetate kinetics allow noninvasive characterization of regional myocardial oxygen demand, which may be useful in assessing the extent of myocardial injury and myocardial oxygen demand of remote myocardium.
\end{abstract}

(Am J Cardiol 1993;71:529-535)
From the Division of Nuclear Medicine, Department of Internal Medicine, University of Michigan, Ann Arbor, Michigan. This study was performed during the tenure of an Established Investigatorship from the American Heart Association (M. Schwaiger) and was supported by Grant R01 HL41047-02 from the National Institutes of Health, Bethesda, Maryland. Manuscript received March 23, 1992; revised manuscript received and accepted September 23, 1992.

Address for reprints: Markus Schwaiger, MD, Division of Nuclear Medicine, University of Michigan Hospital, Ann Arbor, Michigan 48109.
$\mathrm{P}$ ositron emission tomographic imaging (PET) of the heart using radiolabeled fatty acids and glucose analogs has provided unique and clinically useful means of assessing global and regional myocardial metabolism in health and disease states. ${ }^{1-3}$ The abjility of the metabolic tracer carbon-11 (C-11) acetate to nonimvasively depict regional myocardial oxygen consumption and its relative independence of substrate availability has been extensively validated in both animal $^{4-8}$ and human studies. $5,9,10$ This study therefore explores the use of regional myocardial $\mathrm{C}$-11 washout-rate constants measured by dynamic PET imaging as a means of assessing quantitative regional myocardial oxygen consumption in patients who have recently had an acute myocardial infarction. The relation between this technique and other traditional methods of indirectly assessing myocardial oxygen consumption is also explored.

\section{METHODS}

Patient group: Thirty-one patients, 26 men and 5 women, aged 24 to 79 years (mean $57 \pm 14$ ), were enrolled in this protocol. Twenty-four patients were studied within 4 days and the remaining patients within 8 days of acute myocardial infarction. Each was also enrolled in an ongoing thrombolysis and angioplasty (Thrombolysis in Acute Myocardial Infarction trial) research protocol. Thus, they received either recombinant tissue-type plasminogen activator therapy or coronary angioplasty of the culprit artery on hospital presentation. On the basis of their electrocardiographic abnormalities, 18 patients had an acute anterior infarction, whereas the remainder had an inferior or lateral myocardial infarct. All had a significant cardiac enzyme increase consistent with the diagnosis of acute myocardial infarction.

For comparison with normal data, 6 healthy male volunteers aged 25 to 28 years, each with a low-pretest likelihood for cardiac disease and a normal resting electrocardiogram, underwent an identical PET imaging study.

The study protocols were approved by the ethics and radioactive drug research committees of the University of Michigan, and each volunteer or patient signed an informed consent form approved by those committees.

Study protocol: Dynamic PET imaging with C-11 acetate was performed in each subject. Heart rate and 
cuffed blood pressure measurements to be used for subsequent rate-pressure product calculations were recorded during PET data acquisition as were the cardioactive medications that each patient was taking at that time.

Where possible, patients who had a myocardial infarction also underwent an electrocardiogram-gated cardiac blood pool scan within 5 days of presentation, a requirement of the Thrombolysis in Acute Myocardial Infarction trial study protocol. Thus, indexes of left ventricular function obtained close to the time of the PET study were available for analysis in most patients (26 of 31).

Positron emission tomography: PET was performed using a Siemens 931 whole body tomograph. This tomograph has 8 rings, each with 512 detectors and is capable of acquiring 15 simultaneous transaxial planes of data. The carbon-11 acetate was synthesized by a modification of the method previously described by Pike et al. ${ }^{4}$

An initial 10-minute transmission PET study was performed using a ring source of germanium-68/gallium-68. These data were used to ensure correct positioning of the heart in the center of the field of view and for subsequent tissue attenuation correction. Dynamic PET data acquisition was then started as $20 \mathrm{mCi}$ of $\mathrm{C}$ 11 acetate was injected intravenously as a bolus over 15 scconds. Scventecn to 20 frames of dynamic PET data were collected for 30 minutes, with 7 sets of positron tomographic images each being collected for $30 \mathrm{sec}-$ onds, followed by 6 to 9 sets for 60 seconds each, 4 for 120 seconds each and 1 data set each for 180 and 300 seconds.

Image analysis: Using software developed in our laboratory, each frame of the dynamic PET study was reconstructed into 17 transaxial planes. In patients with an inferior myocardial infarction, these data were also reformatted into 12 to 16 cardiac short-axis planes spanning the left ventricle from apex to base. A midleft ventricular slice was then chosen from inspcction of an early frame of the dynamic PET study ( 2 to 4 minutes). At this time, C-11 acetate has been essentially cleared

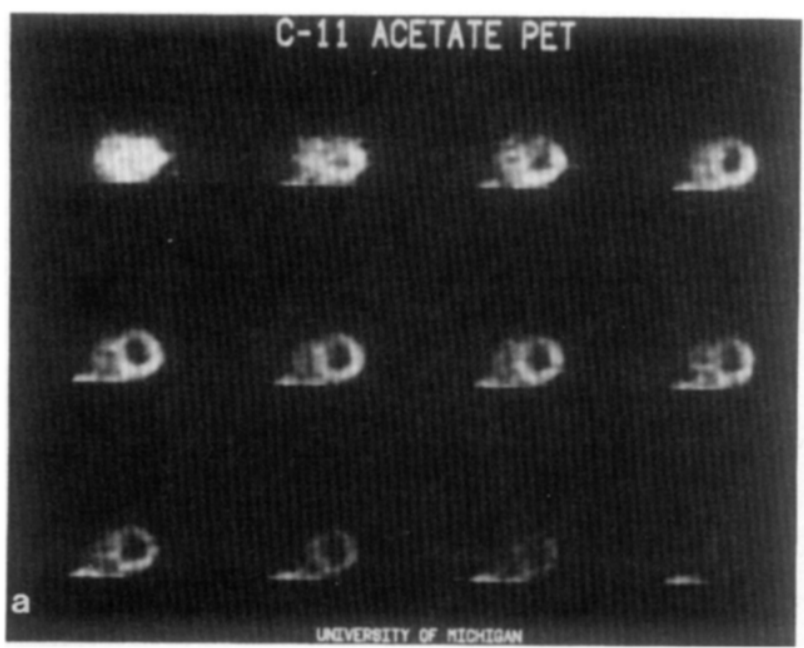

FGURE 1. A representative sequential series of images showing regional carbon-11 (C-11) activity obtained from the midtransaxial myocardial plane acquired over $\mathbf{3 0}$ minutes in a patient with a recent anterior myocardial infaret. Note the reduced initial uptake and then prolonged washout in the infaret zone. The time-activity curves are used for subsequent mono-exponential curve fitting. Note the much lower amplitude and the somewhat different shape to the normal washout curve. PET = positron emission tomography.

from the cardiac blood pool and any myocardial C-11 activity seen predominantly reflects regional myocardial blood flow. ${ }^{11,12}$

In the patients with myocardial infarction, 2 regions of interest were then defined by the operator. The first, representing normal myocardium remote from the infarct region, was chosen in a myocardial segment with apparently normal early $\mathrm{C}$-11 uptake. The second region of interest, representing the infarcted or ischemic zone, was drawn over an area of reduced early C-11 uptake. It too was deliberately made as large as feasible without including transition areas between low "Hlow" and normal "flow." In normal subjects, only 1 large region of interest over the entire left ventricular region was drawn.

Using these regions of interest, time-activity curves were generated from the dynamic PET data set. The descending limb of each curve underwent a monoexponential curve-fitting procedure to the initial linear portion of the first exponential using the least-squares fit method. The earliest data point chosen for curve fitting was based on the earliest frame of data that demonstrated substantial clearance of $\mathrm{C}-11$ activity from the blood pool. The monoexponential curve-fitting algorithm was chosen rather than the biexponential curve-fitting procedure because of the relatively short data acquisition procedure possible in many of these patients and the findings in other laboratories, suggesting that the correlation with myocardial oxygen consumption is only marginally affected using the simpler and reproducible monoexponential fit than the more elaborate curve-fitting approaches. ${ }^{8,13} \mathrm{C}-11$ washout-rate constants $(\mathrm{k} / \mathrm{min})$ were then generated (rate constant $[\mathrm{k} / \mathrm{min}]=0.693 /$ washout halftime [per minute]).

Statistical analysis: Values are given as mean \pm SD. For statistical analysis, comparison of groups was by analysis of variance followed by Bonferroni's modified $t$ test when significant intergroup differences were indicated by analysis of variance or multiple regression analysis. Paired samples were compared using Student's $t$ test for paired data. Statistical significance was indicated by $p$ values $\leq 0.05$.

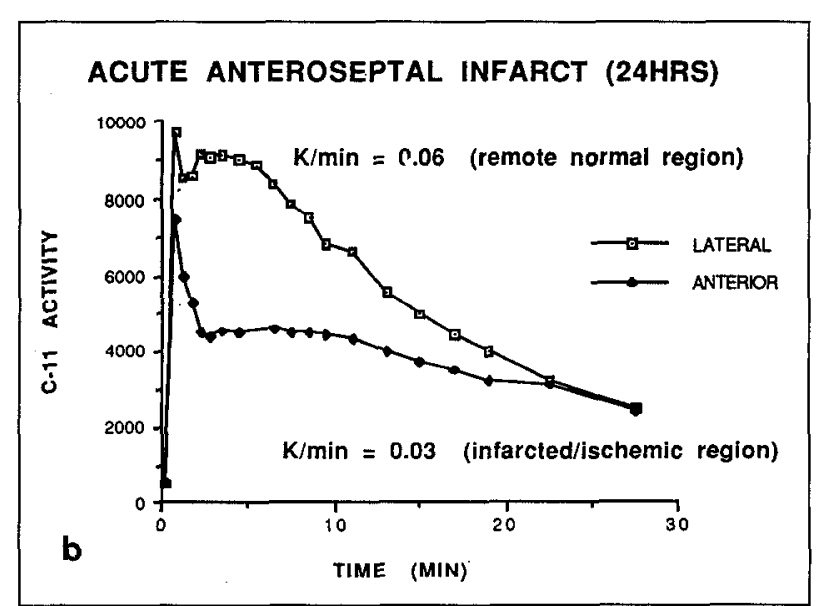




\section{RESULTS}

Positron emission tomography: Each dynamic PET study resulted in high-quality images that were all eminently suitable for analysis. Figures $1 \mathrm{a}$ and $\mathrm{b}$ show a typical series of temporal midventricular images in a patient with an anterior myocardial infarction, and Figure 1b shows the time-activity curves generated from regions of interest placed over normal remote and ischemically damaged myocardium. In this case, the myocardial washout-rate constants were $0.06 / \mathrm{min}$ in the normal region and prolonged to $0.03 / \mathrm{min}$ in the ischemic zone.

Carbon-11 washout-rate constants in normal volunteers and infarct patients: A comparison between the mean C-11 myocardial washout-rate constants in the normal volunteers and in the remote normal, ischemic or infarcted myocardium of the patients is shown in Fig- ure 2. Washout-rate constants in the infarct or ischemic region of patients with inferior or lateral infarcts $(0.034$ $\pm 0.01 \mathrm{k} / \mathrm{min})$ were significantly higher $(\mathrm{p}<0.04)$ than those in corresponding regions of patients with anterior infarcts $(0.025 \pm 0.01 \mathrm{k} / \mathrm{min})$. This may reflect more extensive myocardial damage in left anterior descending artery infarcts, allowing better delineation between infarcted and ischemic tissue. The washout-rate constants of the infarcted/ischemic regions in patients with either anterior or other infarcts were significantly lower ( $p$ $<0.008)$ than those in normal volunteers $(0.051 \pm 0.006$ $\mathrm{k} / \mathrm{min}$ ). Washout-rate constants of the infarcted/ischemic regions were also substantially lower than those for the remote myocardium in individual patients with either anterior $(0.060 \pm 0.017 \mathrm{k} / \mathrm{min}, t$ statistic $=-11.03, p$ $<0.001)$ or other $(0.065 \pm 0.011 \mathrm{k} / \mathrm{min}, t$ statistic $=-7.3$; $\mathrm{p}<0.001)$ infarcts. These findings are in keeping with
FICURE 2. The individual carbon-11 (C-11) acetate washoutrate constants obtained from the normal myocardium of the volunteers (Vols) are compared with those obtained from the remote normal and ischemic/infarcted regions in patients with anterior or nonanterior infarets (as defined from the electrocandiogram). Note that there is a significant difference in mean $\mathbf{k} / \mathbf{m i n}$ between the remote nomal myocardium and the corresponding anterior or nonanterior infarct ischemic/infarct zone ( $<<0.001$ ). The difference between the mean $\mathbf{k} / \mathrm{min}$ of the normal volunteer and that of the nomal remote myocardium of patients with inferior infarcts also just reached statistical significance $(p<0.04)$. MI = myocardial infarction.
FICURE 3. The relation between ratepressure products and carbon-11 washoutrate constants (k/min) of patients with anterior and inferior (OTHER) myocardial infarcts (MI) in the remote nomal (top) and ischemic/ infarct (bottom) regions are shown. Note the reasonable correlations in both ischemic/ infarcted and nomal myocardium, and the wide scatter of data over a wide range of rate-preseure products values.
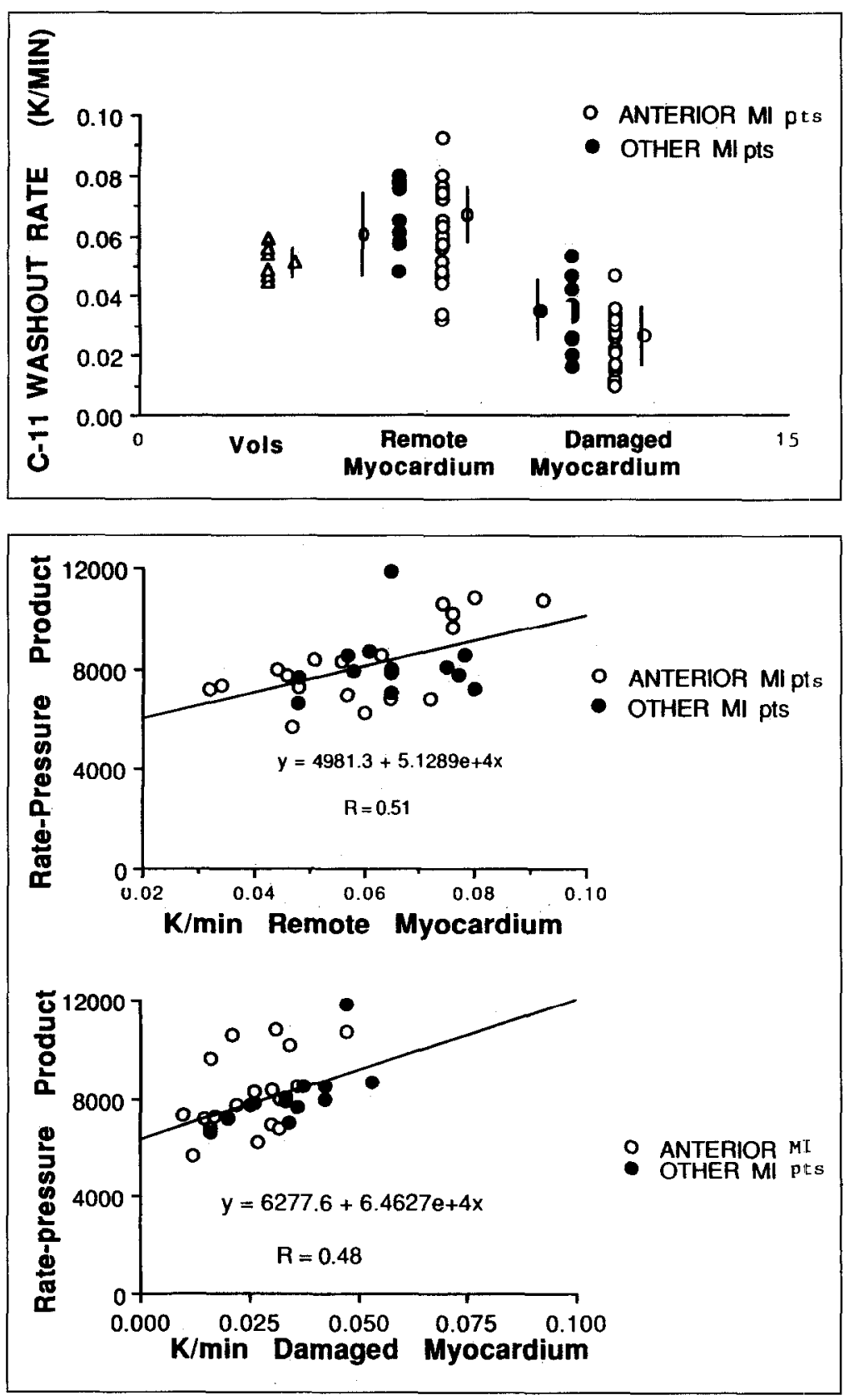
reduced oxidative metabolism in the infarcted/ischemic region. However, the relatively large standard deviations observed suggest heterogeneity of metabolism within infarct-stunned or ischemic myocardium.

Interestingly, the C-11 myocardial washout-rate constants were slower in the normal volunteers than in the remote normal regions of the infarct patients, with patients in the subgroup without anterior infarcts just reaching statistical significance $(\mathrm{p}<0.04)$. This finding may reflect the differing hemodynamic state of the subgroups. The mean rate-pressure products in the volunteers $(6,420 \pm 912)$ were significantly lower $(p<0.03)$ than in either infarct group $(8,124 \pm 1,260$ in the group with inferior infarcts, and 8,167 $\pm 1,601$ in paticnts anterior infarcts).

Interobserver variability of cabon-11 washout measurements: To define possible methodologic factors affecting the scintigraphic measurements in infarct patients, we assessed the interobserver variability of C11 acetate washout kinetics in the infarct as well as remote myocardium of 18 randomly selected patients of the study group. The washout-rate constants in remote myocardium determined by 2 observers were not significantly different $(0.062 \pm 0.013$ vs $0.064 \pm 0.013 \mathrm{k} / \mathrm{min})$ and correlated with an $r$ value of 0.91 (SEE 0.005). In infarcted regions, the values were $0.028 \pm 0.04 \mathrm{k} / \mathrm{min}$ and $0.029 \pm 0.012 \mathrm{k} / \mathrm{min}$ with an $\mathrm{r}$ value of 0.79 (SEE 0.007).

Relation of heart rate-blood pressure product and carbon-11 washoutrate constants: As expected, regional myocardial $\mathrm{C}-11$ washout-rate constants in the normal remote myocardium in patients who had a myocardial infarction were significantly correlated ( $p$ $<0.003$ ) with the rate-pressure product at the time of the study. The individual points are shown in Figure 3 (top). However, the correlation coefficient was only 0.52 (SEE of 1,225 rate-pressure product units) despite a wide range of rate-pressure products and washout-rate constants. Thus, in individual patients with myocardial infarction, the rate-pressure product is only a fair indicator of regional myocardial oxygen use in the nonischemic myocardium remote from the infarct zone.

There was also a significant correlation between the rate-pressure product and regional washout rates (Figure 3 , bottom) in the infarcted or ischemic zone $(r=0.48$;

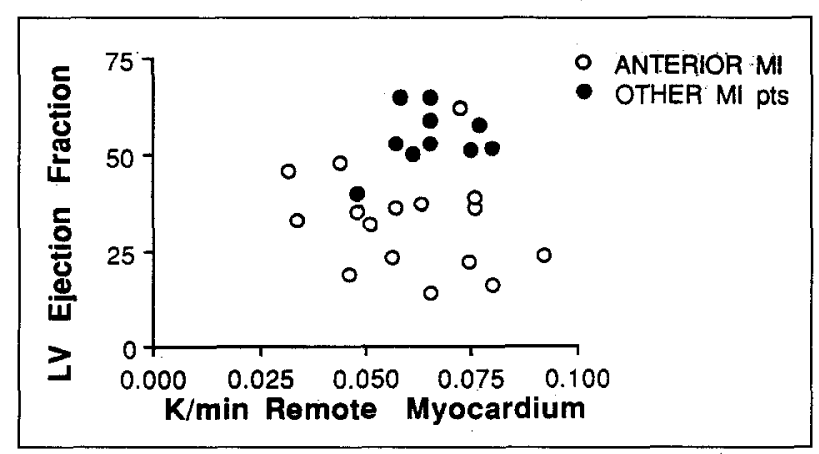

FGURE 4. The lack of correlation between the left ventricular (LV) ejection fractions and washoutrate constants in the nomal remote myocardium in patients with anterior and nonanterior (OTHER) myocardial infarcts (MI) is demonstrated by the scatter plot.
SEE 1,$205 ; \mathrm{p} \leq 0.02$ ). This suggests that variations in left ventricular loading conditions also influence myocardial oxygen consumption in the ischemic zone.

Comparison of left ventricular ejection fraction and carbon-11 washout-rate constants: Left ventricular ejection fraction is an indirect measure of infarct size and, thus, may define the metabolic demand of surviving myocardium. Consequently, its relation with the C-11 washout-rate constant of the remote normal myocardium was examined. The results of this analysis are shown in Figure 4. There was no significant correlation seen $(r=0.1, F$ ratio: $0.02, p>0.9)$ despite a wide range of ejection fractions and washout-rate constants. There was also no relation between rate-pressure product and left ventricular ejection fraction $(\mathrm{r}=0.16$, F ratio: 0.636 , $p>0.5$ ). The lack of relationship may be due to the relative insensitivity of left ventricular ejection fraction measurement to changes in loading conditions caused by the hemodynamic effects of different drug therapies that were given to individual patients.

Other medications such as calcium antagonists, nitrates and angiotensin-converting enzymes had no apparent independent effect on the remote myocardial oxygen consumption using univariate or multivariate analysis. Myocardial oxygen consumption was $0.067 \pm$ $0.10 / \mathrm{min}$ with calcium antagonists versus $0.060 \pm$ $17 / \mathrm{min}$ without treatment $(t=-1.234, \mathrm{p}=0.2)$. For nitrates, the average $\mathrm{C}-11$ clearance-rate constant was $0.061 \pm 0.016$ with versus $0.064 \pm 0.010$ without treatment $(t=0.066 ; \mathrm{p}=0.517)$. For angiotensin inhibitors, it was $0.066 \pm 0.011 / \mathrm{min}$ with versus $0.061 \pm 15 / \mathrm{min}$ without treatment $(t=0.83, \mathrm{p}=0.41)$.

Effect of medication on regional carbon-11 washoutrate constants: Because medical therapy varied from patient to patient, its effect on regional $\mathrm{C}-11$ washout-rate constants could only be assessed for groups of patients taking a given medication. The effect of $\beta$ blockade, which was current therapy for 19 of 31 patients at the time of the PET study, was most interesting. This medication is known to reduce myocardial oxygen consumption. Figure 5 shows that $\beta$ blockade had little effect on myocardial C-11 washout kinetics in

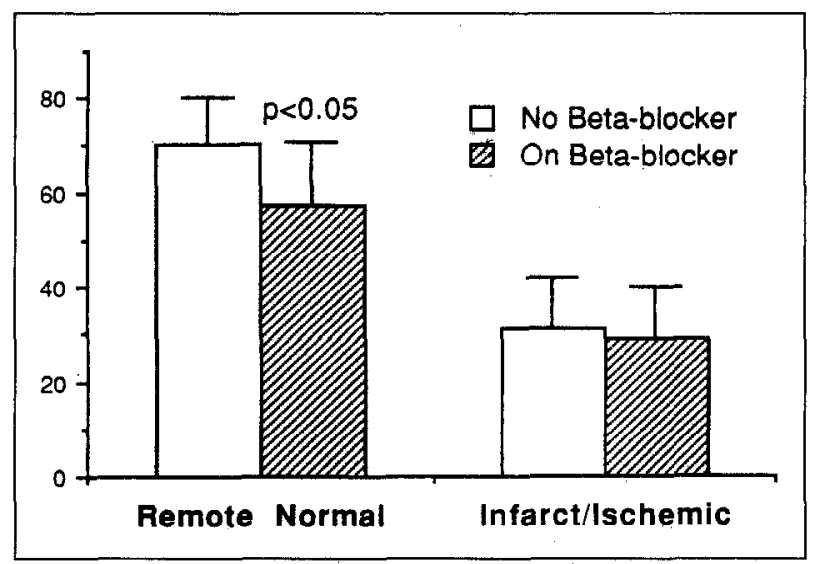

FIGURE 5. Carbon-11 clearancerate constants in the remote myocardium were significantly lower in patients receiving $\beta$ receptor blockers than in those not receiving this modication. A similar but not statistically significant trend was noted for the infaret/ischemic zone. 


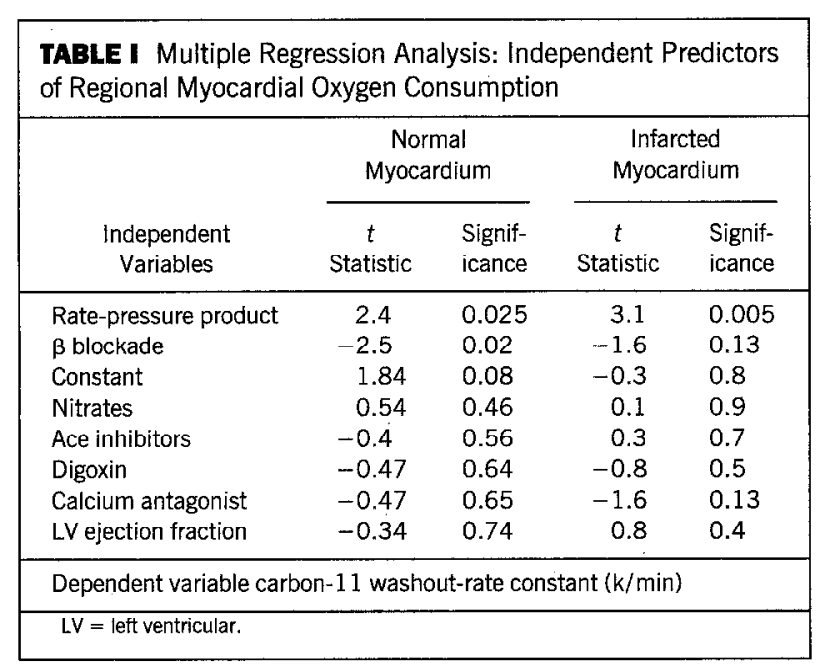

the infarct/ischemic region in patients with $(0.029 \pm$ $0.011 \mathrm{k} / \mathrm{min})$ and without $(0.031 \pm 0.011 \mathrm{k} / \mathrm{min})$ therapy. In contrast, the $\mathrm{C}-11$ washout-rate constants in the remote regions of normal myocardium were significantly lower $(p<0.03)$ in patients with $(0.057 \pm 0.014 \mathrm{k} / \mathrm{min})$ than without $(0.070 \pm 0.011 \mathrm{k} / \mathrm{min}) \beta$-receptor blockers (Figure 5). This difference was not mirrored by similar concomitant differences in mean rate-pressure product $(8,042 \pm 1,506$ with vs $8,320 \pm 1,396$ without $\beta$-blocker therapy; $p=0.6$ ) and left ventricular ejection fractions $(40 \pm 14 \%$ with vs $42 \pm 18 \%$ without $\beta$-blocker therapy; $p=0.8$ ). This apparently independent effect of $\beta$ blockade on regional C-11 acetate clearance in the nonischemic myocardium was confirmed on multiple regression analysis (Table I). In the ischemic regions, this independent effect failed to reach significance. However, a similar trend was seen for the effects of $\beta$ receptor blockers in the ischemic zone. The apparent differential effect of $\beta$-receptor blockers may be due more to technical difficulties with stability of curve fitting in the regions of infarcted/ischemic myocardium than to a true phenomenon.

Correlation of carbon-11 washout rates and clinical parameters: C-11 washout-rate constants in the infarcted and remote myocardium were correlated with clinical parameters (Tables II and III). Among the parameters tested by multiple regression analysis, the time period between onset of symptoms to open infarct artery and location of infarct significantly affected the C11 acetate washout-rate constants in the infarct territory. In addition, C-11 acetate kinetics were significantly related to the product of heart rate and blood pressure in the infarcted territory. None of the other parameters, as indicated in Tables II and III, showed a significant relation to the scintigraphic findings.

\section{DISCUSSION}

This study extends the preliminary findings of Walsh et $\mathrm{al}^{14}$ in that it investigates in more detail the relation between regional myocardial oxygen consumption as measured by $\mathrm{C}-11$ acetate washout-rate constants and other clinical and investigative methods of assessing myocardial work in a larger group of patients after a

\begin{tabular}{|c|c|c|c|c|}
\hline & \multicolumn{4}{|c|}{ Dependent Variables } \\
\hline & \multicolumn{2}{|c|}{$\begin{array}{l}\text { C-11 Acetate- } \\
\text { (k/min) Ischemic } \\
\text { Myocardium }\end{array}$} & \multicolumn{2}{|c|}{$\begin{array}{l}\text { C-11 Acetate- } \\
\text { (k/min) Remote } \\
\text { Myocardium }\end{array}$} \\
\hline & $\mathbf{r}$ & $\mathrm{p}$ Value & $r$ & $p$ Value \\
\hline Age of pt. & - & 0.5 & 0.26 & 0.1 \\
\hline Sex & 0.29 & 0.1 & 0.3 & 0.1 \\
\hline $\begin{array}{l}\text { Time to PET (days } \\
\text { after MI) }\end{array}$ & 0.26 & 0.13 & 0.22 & 0.3 \\
\hline $\begin{array}{l}\text { Time to thrombolysis } \\
\text { (hr) (24 pts.) }\end{array}$ & 0.18 & 0.4 & - & 0.9 \\
\hline $\begin{array}{l}\text { Time to PTCA (hr) } \\
\text { (23 pts.) }\end{array}$ & - & 0.5 & - & 0.8 \\
\hline $\begin{array}{l}\text { Time to open vessel } \\
\text { (22 pts.) }\end{array}$ & 0.42 & 0.048 & - & 0.15 \\
\hline Infarct location & 0.411 & 0.021 & 0.2 & 0.35 \\
\hline $\begin{array}{l}\text { Double product } \\
(\mathrm{HR} \times \mathrm{SBP})\end{array}$ & 0.49 & 0.005 & 0.51 & 0.003 \\
\hline $\begin{array}{l}\text { Pre-PTCA stenosis \% } \\
\quad \text { (24 pts.) }\end{array}$ & - & 0.4 & - & 0.5 \\
\hline \multicolumn{5}{|c|}{$\begin{array}{l}\text { C-11 = carbon-11; HR = heart rate; PET = position emission tomography } \\
\text { Pre-PTCA = infarct vessel percent stenosis before percutaneous transluminal coronary } \\
\text { angioplasty; SBP }=\text { systolic blood pressure; Time to open vessel }=\text { time to to } \\
\text { thrombolysis if infarct vessel is patent at early catheterization iust before PTCA, or time } \\
\text { to PTCA if vessel is still occluded at PTCA. }\end{array}$} \\
\hline
\end{tabular}

TABLE III Stepwise Multiple Regression Analysis (dependent variable: $k$ ischemic region)

\begin{tabular}{|ccc|}
\hline & $t$ Statistic & $\mathrm{p}$ Value \\
\hline Infarct location & -2.7 & 0.016 \\
Time to open vessel & -2.17 & 0.043 \\
Double product & 3.1 & 0.006 \\
\hline $\begin{array}{l}\text { Time to open vessel = time to thrombolysis if infarct vessel is patent at early } \\
\text { catheterization just before percutaneous transluminal coronary angioplasty, or time to } \\
\text { percutaneous transiuminal cornary angioplasty if vessel is still occluded at percutane- } \\
\text { ous transluminal coronary angioplasty. }\end{array}$ \\
\hline
\end{tabular}

myocardial infarction. It has shown the relatively loose association of regional $\mathrm{C}-11$ acetate washout-rate constants with global estimates of regional myocardial oxygen consumption such as the rate-pressure product. It has also demonstrated for the first time the effect of cardiac medications such as $\beta$-receptor blockers on regional myocardial oxygen consumption.

Carbon-11 acetate kinetics in the remote nomal myo-cardium: Rate-pressure product shows excellent correlation with invasive measurements of global myocardial oxygen consumption in normal volunteers and patients with diffuse heart disease. ${ }^{15,16}$ However, the inherent limitation of the rate-pressure product as an estimate of either global or regional myocardial oxygen consumption in ischemic heart disease is suggested in the data obtained from the normal remote myocardium in the infarct patients. Although there was still a statistically significant correlation between $\mathrm{C}-11$ washout-rate constants and the rate-pressure product, $\mathrm{C}-11$ washoutrate constants in the remote normal myocardium of patients with myocardial infarction had substantially greater variability than those observed in normal volunteers $9,10,17$ and those in patients with diffuse heart disease $^{18}$ over a similar range of rate-pressure products. These data suggest that a global predictor of myocardial oxygen demand is only likely to be closely related to 
regional oxygen consumption when regional loading and perfusion are uniform throughout the heart. This is clearly not the case in ischemic heart disease. The lack of prediction of regional myocardial oxygen consumption by the rate-pressure product suggested by this study has direct implications in the design of studies evaluating the effect of drugs or other interventions on myocardial oxygen consumption in patients with coronary artery disease.

The lack of correlation between regional C-11 clearance in remote myocardium and the left ventricular ejection fraction, another direct measure of ventricular dysfunction, is also not surprising because of the latter's relative insensitivity to hemodynamic loading conditions. Thus, C-11 acetate kinetics are able to provide data on regional oxygen consumption that cannot really be easily obtained by other noninvasive methods.

Effects of medications: The value of assessment of regional myocardial oxygen consumption with C-11 acetate and PET is best illustrated by the observations on the effect of $\beta$-receptor blocker therapy on regional $\mathrm{C}$-11 acetate clearance soon after myocardial infarction. Beta blockade has been used in patients after myocardial infarction because of its ability to decrease long-term morbidity and mortality. ${ }^{19,20}$ The main action of $\beta$ blockade is to inhibit sympathetic stimulation of the heart, thus reducing oxygen consumption. This is usually manifest by reduction in heart rate and blood pressure as well as by indexes of myocardial contractility. In addition, metabolic effects of $\beta$ blockade have been suggested which include increased carbohydrate use. ${ }^{21}$ This study has shown that in remote uninjured myocardium, $\beta$-receptor blocker therapy exerts an effect on regional myocardial oxygen consumption not confined to a reduction in rate-pressure product and possibly reflecting protection of the heart from increased levels of plasma catecholamines or decreased contractility.

Interestingly, similar effects were not observed with other medications used in this patient group. This is not surprising for nitrates whose main effect is vasodilation, predominantly of the peripheral veins, reducing myocardial preload as well as improving flow to regions of myocardium beyond coronary stenoses. As such, it is not considered to have a direct effect on the contractile state of the heart. ${ }^{22}$ The finding of a lack of a significant effect on myocardial oxygen consumption by either calcium antagonists or angiotensin-converting enzyme inhibitors is also in keeping with their known effects of coronary and peripheral vasodilation. ${ }^{22,23}$ However, this finding needs to be interpreted with caution because the numbers of patients taking these agents were small and various subclasses of calcium antagonists were lumped together. Further studies are needed to expand these preliminary findings.

Carbon-11 acetate kinetics in the infarcted myocardium: This study confirms the findings of others that C-11 washout-rate constants are reduced in ischemically injured myocardium ${ }^{2,5,14}$ and, thus, supports the concept of reduced oxidative metabolism in such regions. It also raises the possibility of external work load requirements affecting myocardial oxygen con- sumption in these regions just as they appear to in the remote myocardium. There was a significant relation between myocardial work load and C-11 washout-rate constants in the infarct territory. The weak relation may be explained by the admixture of viable and necrotic tissue during the subacute phase of myocardial infarction. These data indicate that oxidative metabolism of injured myocardium is modified by overall ventricular work load despite the presence of regional wall motion abnormalities in the infarct territory. Since reduction of oxygen demand is thought to be beneficial in ischemically jeopardized myocardium, such measurements of regional oxidative metabolism may be helpful in pathophysiologic and pharmacologic evaluation of acutcly injurcd myocardium. Such measurements may reflect accurately the severity of ischemic damage as suggested by the significant relation between time of ischemia, prior thrombolysis, and C-11 washout rates defined by multiple regression analysis (Tables $I I$ and III). Therefore, early metabolic evaluations of ischemically injured myocardium by $\mathrm{C}-11$ acetate may provide information about tissue viability as recently suggested by Gropler et $\mathrm{al}^{12}$ in a small patient population. Further studies are required to compare $\mathrm{C}-11$ acetate and ${ }^{18} \mathrm{~F}$-2-deoxy-2fluro-D-glucose in their role in predicting myocardial salvage after reperfusion therapy.

However, the quantitative aspects of the analysis of $\mathrm{C}$-11 tissue kinetics need to be interpreted with caution because the relation between $\mathrm{C}-11$ washout-rate constants and actual oxidative metabolism is not as well established for regions with blood flow impairment and variable tissue viability as in myocardium with unrestricted blood flow. Animal studies during acute ischemia suggest a maintained relation of $\mathrm{C}-11$ washout and oxygen consumption under such low flow conditions. ${ }^{24}$ Preliminary clinical data by Melin et al ${ }^{25}$ indicate that C-11 washout-rate constants are closely related to reduced blood flow in the infarct territory. Because blood flow and oxygen consumption are closely coupled in normal and ischemic myocardium, separation of these 2 physiologic parameters may be difficult. Future studies directly comparing regional blood flow and oxidative metabolism are needed to define the diagnostic gain of the assessment of oxygen consumption over flow determination alone for the definition of tissue viability. ${ }^{26}$

Conclusion: This study illustrates the unique potential of regional $\mathrm{C}-11$ washout-rate kinetics as an index of regional myocardial oxygen consumption in patients soon after myocardial infarction in clinical situations where there is a variable degree and extent of damaged myocardium. Regional assessment of myocardial oxygen consumption may assess the presence of viable myocardium early after reperfusion therapy. However, further studies are required relating these metabolic measurements with long-term outcome of regional myocardial function. Besides the possible application of this technique in the management of patients with acute myocardial infarction, regional measurements of oxygen consumption will be useful in the characterization of pathophysiology and pharmacology during the subacute phase of the myocardial injury. Objective criteria of re- 
gional oxygen consumption may be needed to optimize therapeutic strategies to reduce myocardial damage and to enhance tissue recovery. Using PET measurements, various drug regimens could be compared based on regional metabolic evaluation rather than on longitudinal studies assessing tissue recovery. Since PET remains an expensive technology, such a quantitative technique may be most useful in clinical research requiring end points for therapeutic interventions in patients with acute myocardial infarction.

Acknowledgment: We gratefully acknowledge the help in data retrieval given by Sheila Squicciarini, the provision of C-11 acctatc by Thomas Mangner, and the staff of the University of Michigan PET Center.

\section{REFERENCES}

1. Bergmann S, Fox K, Geltman E, Sobel B. Positron emission tomography of the heart. Prog Cardiovasc Dis 1985;28:165-194.

2. Brunken RC, Schwaiger M, Grover-McKay M, Pheips ME, Tillisch JH, Schelbert HR. Positron emission tomography detects tissue metabolic activity in myocardial segments with persistent thallium perfusion defects. I Am Coll Cardiol 1987; 10:557-567.

3. Schelbert HR, Buxton D. Insights into coronary artery disease gained from metabolic imaging. Circulation 1988;78:496-505.

4. Pike VW, Eakins MN, Allan RM, Selwyn AP. Preparation of $[1-11 \mathrm{C}]$ acetate - an agent for the study of myocardial metabolism by positson emission tomography. Int I Appl Radiat Isot 1982;33:505-512.

5. Brown M, Marshall DR, Sobel BE, Bergmann SR. Delineation of myocardial oxygen utilization with carbon-11-labeled acetate. Circulation 1987;76:687-696.

6. Brown MA, Myears DW, Bergmann SR. Validity of estimates of myocardial oxidative metabolism with carbon-11 acetate and positron emission tomography despite allered patterus of substrate utilization. $J$ Nucl Med 1989;30:187-193.

7. Buxton DB, Schwaiger M, Nguyen N, Phelps ME, Schelbert HR. Radiolabeled acetate as a tracer of myocardial tricarboxylic acid cycle flux. Circ Res 1988;63: $628-634$.

8. Buxton DB, Nienaber CA, Luxen A, Ratib O, Hansen H, Phelps ME, Schelbert HR. Noninvasive quantitation of regional myocardial oxygen consumption in vivo with [1-11C] acetate and dynamic positron emission tomography. Circulation 1989; 79:134-142.

9. Schwaiger M, Hutchins GD, Bergin P, Mangner T, Kalff V, Kuhl DE. Independence of $\mathrm{C}-11$ acetate kinetics from dietary state in the human heart (abstr). $J$ Nucl Med 1989;30:837.

10. Armbrecht JJ, Buxton DB, Brunken RC, Phelps ME, Schelbert HR. Regional myocardial oxygen consumption determined noninvasively in humans with [1-11C] acetate and dynamic positron tomography. Circulation 1989;80:863-872.

11. Chan SY BR, Phelps ME, Schelbert HR. Use of the metabolic tracer carbon11 acetate for evaluation of regional myocardial perfusion. $J$ Nucl Med 1991;32: $665-672$.

12. Gropler K, Siegel B, Geltman E. Myocardial uptake of carbon- 11 acetate as an indirect measurement of regional myocardial blood flow. $J$ NuCl $\mathrm{Med} 1991 ; 32$ : 245-251.

13. Brown MA, Mycars DW, Bergmann SR. Noninvasive assessment of canine myocardial oxidative metabolism with carbon-11 acetate and positron emission tomography. J Am Coll Cardiol 1988;12:1054-1063.

14. Walsh MN, Geltman EM, Brown MA, Henes CG, Weinheimer Cr, Sobel EE, Bergmann SR. Noninvasive estimation of regional myocardial oxygen consumption by positron emission tomography with carbon-11 acetate in patients with myocardial infarction. $J$ Nucl Med 1989:30:1798-1808.

15. Gobel FL, Nordstrom LA, Nelson RP, Jorgensen CR, Wang $Y$. The pressure rate product as an index of myocardial oxygen consumption during exercise in patients with angina pectoria. Circulation 1978;57:549-556.

16. Kitamura K, Jorgensen CR, Gobel FL, Taylur HL, Wang Y. Henodynamic correlates of myocardial oxygen consumption during upright exercise. $J$ Appl Physiol $1972 ; 32: 516-522$

17. Henes CG, Bergmann SR, Walsh MN, Sobel BE, Geltman EM. Assessment of myocardial oxidative metabolic reserve with positron emission tomography and carbon-11 acetate. $J$ Nucl Med 1989;30:1489-1499.

18. Savas V, Kalff V, Bergin $P$, Nabel E, Kuhl D, Schwaiger M. C-11 acetate kinetics as a non-invasive marker of myocardial oxygen consumption in patients with aortic valve disease (abstr). Circulation 1989;80(suppl II):II-515.

19. Multicenter International Study. Improvement in prognosis of myocardial infarction by long term beta-adenoreceptor blockade using practolol. BMJ 1975.

20. Norwegian Study Group. Timolol induced reduction in mortality and reinfarction in patients surviving acute myocardial infarction. $N$ Engl J Med 1981; 304:801-807.

21. Eichorn E, Bedotto J, Malloy C, Hatfield B, Deitchman D, Brown M, Willard J, Grayburn P. Effect of beta-adrenergic blockade on myocardial function and energetics in congestive heart failure: improvements in hemodynamic, contractile, and diastolic performance with bucindolol. Circulation 1990:82:473-483.

22. Rutherford D, Cohen P. Chronic ischemic heart disease. In: Braunwald E, ed. Heart Disease: A Textbook of Cardiovascular Medicine. 3rd ed. Philadelphia: WB Saunders, 1988

23. Ader R, Chatterjee $K$, Ports $T$, Brundage $B$, Hiramatsu $B$, Parmley W. Immediate and sustained hemodynamic and clinical improvement in chronic heart failure by anı ural angiviensin-convertiug enzyme inhibitor. Circulation 1980;61: 931-937.

24. Armbrecht JJ, Buxton DB, Schelbert HR. Validation of [1-11C] acetate as a tracer for noninvasive assessment of nxidative metaholism with positron emission tomography in normal, ischemic, postischemic, and hyperemic canine myocardium. Circulation 1990:81:1594-1605.

25. Melin JA, Vanoverschelde $\mathrm{J}$, Bol A, Wijns W. Regional oxidative metabolism in patients with reperfused infarction: relation to regional blood flow and glucose uptake (abstr). Circulation 1989;80(suppl II):II-378.

26. Buck A, Wolpers H, Hutchins G, Savas V, Mangner T, Nguyen N, Schwaiger M. Effect of carbon-11-acetate recirculation on estimates of myocardial oxygen consumption by PET. $I$ Nucl Med 1991;32:1950-1957. 